\title{
The Miniaturization of Cardiac Implantable Electronic Devices: Advances in Diagnostic and Therapeutic Modalities
}

\author{
Richard G. Trohman *, Henry D. Huang and Parikshit S. Sharma
}

Section of Electrophysiology, Arrhythmia and Pacemaker Services, Division of Cardiology, Department of Internal Medicine, Rush University Medical Center, Chicago, IL 60612, USA; Henry_D_Huang@rush.edu (H.D.H.); Parikshit_S_Sharma@rush.edu (P.S.S.)

* Correspondence: rtrohman@rush.edu; Tel.: +1-312-942-2887

Received: 26 August 2019; Accepted: 17 September 2019; Published: 21 September 2019 updates

\begin{abstract}
The Fourth Industrial Revolution, characterized by an unprecedented fusion of technologies that is blurring the lines between the physical, digital, and biological spheres, continues the trend to manufacture ever smaller mechanical, optical and electronic products and devices. In this manuscript, we outline the way cardiac implantable electronic devices (CIEDs) have evolved into remarkably smaller units with greatly enhanced applicability and capabilities.
\end{abstract}

Keywords: implantable cardioverter defibrillators; cardiac pacing; cardiac resynchronization therapy; implantable heart failure sensor; implantable loop recorder

\section{Introduction}

The Fourth Industrial Revolution [1], characterized by an unprecedented fusion of technologies that is blurring the lines between the physical, digital, and biological spheres, continues the trend to manufacture ever smaller mechanical, optical and electronic products and devices [2]. In this manuscript, we outline the way cardiac implantable electronic devices (CIEDs) have evolved into remarkably smaller units with greatly enhanced applicability and capabilities.

\section{Prevention of Sudden Death}

The current annual incidence of sudden cardiac death in the United States is in the range of 180,000 to 450,000 per year [3,4]. Although the prevalence of malignant ventricular arrhythmias as the etiology has declined, they remain the most common cause of cardiac arrest [3]. Multiple studies have confirmed the preeminence of implantable cardioverter defibrillators as the treatment of choice for primary and secondary prevention of sudden cardiac death [5].

The first implantable defibrillator (AID) was large $(289 \mathrm{~g}, 150 \mathrm{~mL})$, required a median sternotomy to open to place patch electrodes and two screw-in sensing leads on the heart's epicardial surface. The pulse generator had to be implanted subcutaneously in the abdominal region [6].

The earliest implantable defibrillators had no or very limited capabilities with respect to pacemaker function, stored telemetry, and arrhythmia discrimination ability [6]. Modern devices can perform virtually all the functions of a pacemaker, including cardiac resynchronization therapy pacing, storing large amounts of arrhythmia and other physiologic data, and have some ability to discriminate between supraventricular and ventricular tachycardias [7].

Modern implantable cardioverter defibrillator (ICD) systems are implanted under the skin of the upper chest area and have two basic elements, a pulse generator and 1-3 leads placed in the cardiac chambers or epicardially via the coronary sinus into a cardiac vein to pace the left ventricle. 
They are available as single-chamber (right ventricular lead only), dual-chamber (right atrial and right ventricular leads) and triple-chamber devices (right atrial, right ventricular and left ventricular leads) capable of bradycardia, anti-tachycardia (termination), and cardiac resynchronization (triple-chamber only) pacing [8].

The majority of an ICD pulse generator consists of the battery and a capacitor (the component that stores and delivers charges). Defibrillators must store energy to deliver lifesaving shocks. Developing capacitors which required a minimum of stored energy but still delivered enough energy for defibrillation without affecting the ICD service life was pivotal in size reduction [9].

Capacitors are electronic components that take advantage of the ability of electrical fields to reach across an insulator. They consist of two flat plates made from a conducting material, separated by a thin insulating material. When a battery is connected to the conducting plates, the battery voltage negative side pushes negative charges toward one plate. The positive battery voltage side simultaneously pulls electrons (negative charge) away from the second plate. The electric field that rapidly builds between plates permits current to flow. As the circuit's negative plate fills with electrons, the electric field created pushes electrons away from the plate on the opposite side of the insulator toward the positive battery voltage side. When current flows, an excess of electrons builds up on the negative capacitor plate as the positive side develops an electron deficiency, creating a potential difference (voltage) between the capacitor's plates. Current only flows briefly. As electrons accumulate on the negative plate and are depleted on the positive plate, the differences in charge between plates increases and the voltage between them increases. The voltage increases until the capacitor voltage is equal to the battery voltage. Once the voltages are equal, current flow ceases, and the capacitor is charged. When the capacitor has been charged, the battery may be disconnected and the voltage remains in the capacitor (does not depend on the battery for its continued presence). Thus capacitors are capable of storing change (a quality known as capacitance) [10].

Electrolytic capacitors can hold a massive electric charge in their tiny footprint [10]. Current implantable cardioverter defibrillators (ICDs) are minicomputers that and are small enough to fit in the palm of your hand. The newest devices weigh as little as $70 \mathrm{~g}$ at a volume of less than $40 \mathrm{~mL}$ and are less than a centimeter thick [11].

The subcutaneous implantable cardioverter defibrillator (S-ICD) was approved for use in the United States in 2012 [12]. Although innovative, it is clearly a step backward from miniaturization and enhanced capability. S-ICDs do not have the capability of providing bradycardia pacing, antitachycardia pacing or cardiac resynchronization therapy. Even the third-generation pulse generator $\left(E^{2} M_{B L E M}{ }^{\mathrm{TM}}\right.$ MRI S-ICD System, Boston Scientific, St. Paul, MN, USA) is reminiscent of the early, bulky ICD models. It weighs $130 \mathrm{~g}$ and its volume is $59.5 \mathrm{~cm}^{3}$. Its height, width and thickness are $69.1 \mathrm{~mm}, 83.1 \mathrm{~mm}$, and $12.7 \mathrm{~mm}$, respectively [13].

S-ICDs may be considered for: (1) Younger patients due to the expected subcutaneous lead longevity and a desire to avoid chronic transvenous leads; (2) ICD candidates without a current or anticipated need for pacing; (3) Patients at high risk for bacteremia, including those with end-stage renal disease on hemodialysis or with chronic indwelling endovascular catheters; (4) Patients with limited vascular access or prior transvenous ICD complications [12].

Inappropriate shocks, mainly resulting from oversensing, are a significant limitation of S-ICDs. Non-invasive reprogramming options are not always successful and device explantation may be required.

\section{Advances in Implantable Cardioverter Defibrillator (ICD) Lead Technology}

Older DF-1 leads consist of bifurcated (in a single-coil lead) or trifurcated (in a dual-coil lead) header connector pins. One pin is a pace-sense connector and the other(s) are high-voltage coil connectors. The connectors are joined in a yoke that incorporates them into one lead body. The distal end of the lead is implanted in the right ventricle. The pulse generator header may have three plugs for connector insertion (dual-coil lead, single-chamber ICD), four plugs (dual-coil lead, dual-chamber 
ICD), or five plugs (dual-coil lead, cardiac resynchronization therapy defibrillator). Altogether, large headers combined with the bi/trifurcated yoke result in an ICD system that is quite bulky [12].

The four-pole inline DF-4 connector system was endorsed by the Association for the Advancement of Medical Instrumentation in 2011 [14]. DF-4 connectors are designed to facilitate lead-to-device connection, minimize the risk of incorrect device connection, and reduce the bulk of the device. Unfortunately, these advantages are achieved at the expense of additional connectivity, which precludes strategies such as adding a subcutaneous or azygos vein coil to overcome the problem of high defibrillation energy requirements $[14,15]$.

\section{Pacing for Bradycardia}

Cardiac pacemakers were invented in 1949. The original versions were bulky boxes plugged into walls for power [16]. In 1958, three developments paved the way for modern cardiac pacing. Furman introduced a transvenous electrode and successfully stimulated the right ventricle (RV) for 96 days. Medtronic (Minneapolis, MN, USA) developed a four-inch, battery-powered box that could be taped to a patients' chest and Lillehei and Bakken reported efficacy of a battery-powered external pacemaker in 18 patients. The first wearable pacemaker weighed $283 \mathrm{~g}$. Later that year, Senning and Elmqvist performed the first pacemaker implant using an epicardial lead [16-18]. Soon thereafter devices became small enough to be implanted internally, but the need for frequent recharging was problematic. Medtronic produced the first commercially implantable pacemaker technologies in 1960 [16]. Rate-adaptive pacing first appeared in the 1980s. Despite development of multiple sensor types, as well as blending of sensor technologies, there has been no significant observable symptom benefit or impact on clinical outcomes from different sensors or combination of sensors [19]. Magnetic Resonance Imaging (MRI) conditional devices have been developed over the last 10 years [16].

It is currently estimated that nearly one million patients worldwide receive conventional permanent transvenous cardiac pacemakers annually. Pacemakers are limited by device-related complications. Adverse events related to cardiac pacemakers occur in $10 \%$ of recipients [20]. Typically these events are related to the surgical pocket, pulse generator or transvenous lead(s). Leads are vulnerable to fracture, insulation failure or dislodgement and can also cause venous thrombosis/occlusion, tricuspid regurgitation, and cardiac perforation. Lead-related endocarditis is a significant concern, with mortality rates reported between 12-31\% [21]. Pulse generators have been associated with pocket hematoma, skin erosion and infection.

Although pulse generators have grown smaller and leads are thinner, reduction in pacing lead size has been a mixed blessing. Smaller leads appear to be more likely to result in cardiac perforation [22]. Additionally, device infection is on the rise [23]. FINELINE II ${ }^{\mathrm{TM}}$ Sterox EZ Leads (Boston Scientific, Minneapolis, MN, USA) screw-in active-fixation leads, have been used worldwide since 2001. A mannitol coating surrounds the helix, facilitating easy passage through the great veins of the thorax. The mannitol melts in the cardiac chamber allowing helix fixation. Lead durability has been proven satisfactory [24]. Unfortunately, Fineline ${ }^{\mathrm{TM}}$ leads are at high-risk for disruption (severance) with traction and difficulties during lead extraction procedures have led many operators to avoid use of these leads.

In response to these concerns, two leadless cardiac pacemakers have been developed for patients requiring permanent ventricular pacing. Two leadless pacing systems have been available: the Micra Transcatheter Pacing system (Medtronic, Inc. Minneapolis, MN) and the Nanostim Leadless Cardiac Pacemaker (Abbott; subsidiary St. Jude Medical, St. Paul, MN, USA). Both systems provide right ventricular sensing, pacing, and rate responsiveness. While both of these pacing systems are delivered percutaneously via the femoral vein through a catheter delivery system, they differ with respect to size, fixation to the myocardium, and responsiveness. The Nanostim recently had two major recalls: The first due to premature battery failure and the second due to spontaneous detachment of the docking button (a feature designed to allow retrieval of the Nanostim). Abbott is maintaining a worldwide 
halt on implantations of the Nanostim leadless pacemaker after reports surfaced of problems with the device's docking button [25]. Hence, the remainder of this discussion will focus on Micra.

Micra has a length of $25.9 \mathrm{~mm}$, a volume of $0.8 \mathrm{~mL}$ and weighs $2 \mathrm{~g}$. Its size has been compared to a "large vitamin" (Figure 1) [26]. A percutaneous transfemoral venous catheter-based approach is used to introduce the device into the right ventricle. Micra requires a 23 French (inner diameter)/27 French (outer diameter) sheath. Four nitonol tines are used to affix the device to the right ventricular septal myocardium. Multiple fluoroscopic views are used to ascertain fixation. At least two tines are required to assure stable fixation. Micra uses conventional radiofrequency communication to confirm acceptable pacing and sensing parameters and provides rate responsiveness using a 3-axis accelerometer. Micra is tethered to the introducer sheath and can be retrieved and repositioned if unacceptable pacing/sensing parameters are recorded. The introducer sheath and a goose neck snare can be used to remove a device that is no longer tethered.
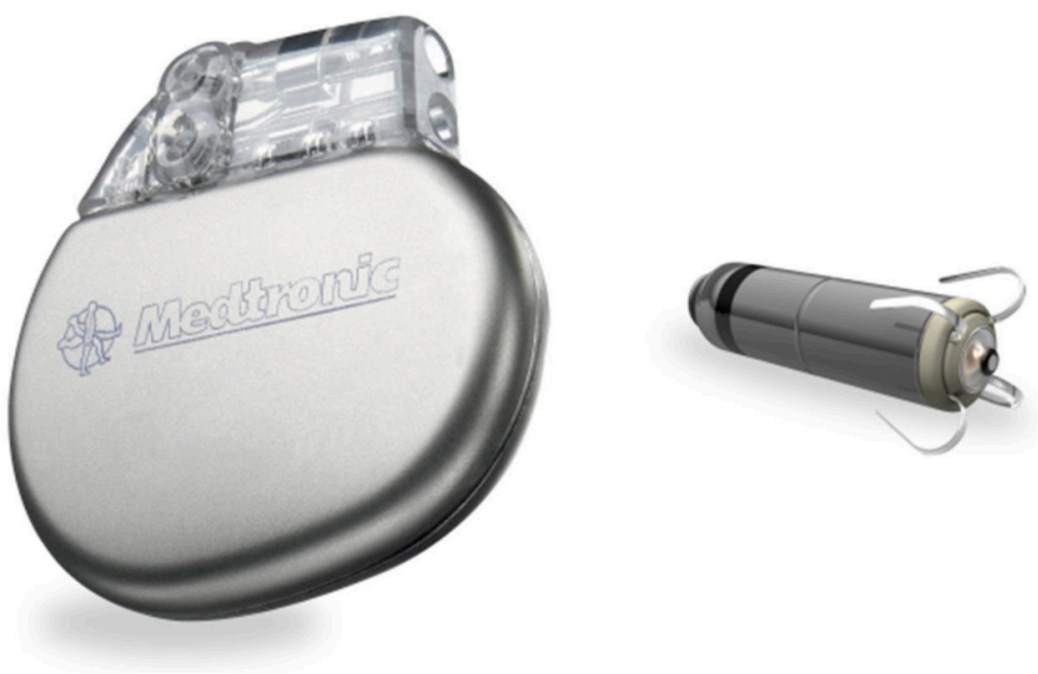

Figure 1. A typical dual-chamber pacemaker (left) and the Micra (right). Reproduced with permission from reference [26] and Medtronic, Inc.

In the Micra investigational device exemption prospective study, implantation was successful in 719 of 725 (99.2\%) patients. Complications occurred in $3.4 \%$ of patients, including cardiac perforation $(1.5 \%)$, vascular complications $(0.7 \%)$, venous thromboembolism $(0.3 \%)$, and increased pacing thresholds $(0.3 \%)$. There were no device dislodgements. The trial included a pre-specified historical cohort of patients implanted with a single-lead transvenous permanent pacemaker. Micra implantation was associated with a $48 \%$ reduction in major complications compared to the transvenous permanent pacemaker group [27].

Despite these encouraging results, the downside of chronic right ventricular pacing (mechanical dyssynchrony leading to heart failure) limits the current use of leadless pacing. We await development of leadless VDD systems, dual-chamber systems and possibilities for cardiac resynchronization therapy to facilitate the expansion of leadless pacing to a broader group of patients.

\section{Pacing to Treat Heart Failure}

Cardiac resynchronization therapy (CRT) is applicable to $25-30 \%$ of patients with symptomatic systolic heart failure. Patients with left bundle branch block (LBBB) and QRS duration $\geq 150 \mathrm{~ms}$ are seen to benefit the most from CRT. Current evidence suggests that approximately $30 \%$ of the patients who are selected for CRT do not respond to this therapy [28]. However, there is a lack of standard definitions for CRT response and the spectrum of CRT response and reported response rates vary widely depending on metrics used and whether a placebo effect is considered [28]. 
CRT may be employed in association with bradycardia pacing (CRT-P) or an implantable cardioverter defibrillator (CRT-D). CRT is usually achieved via biventricular pacing. Right ventricular leads are placed via the great veins of the thorax. Left ventricular leads are also advanced via the great veins of the thorax and ultimately positioned in a branch of the coronary sinus (Figure 2) [29].

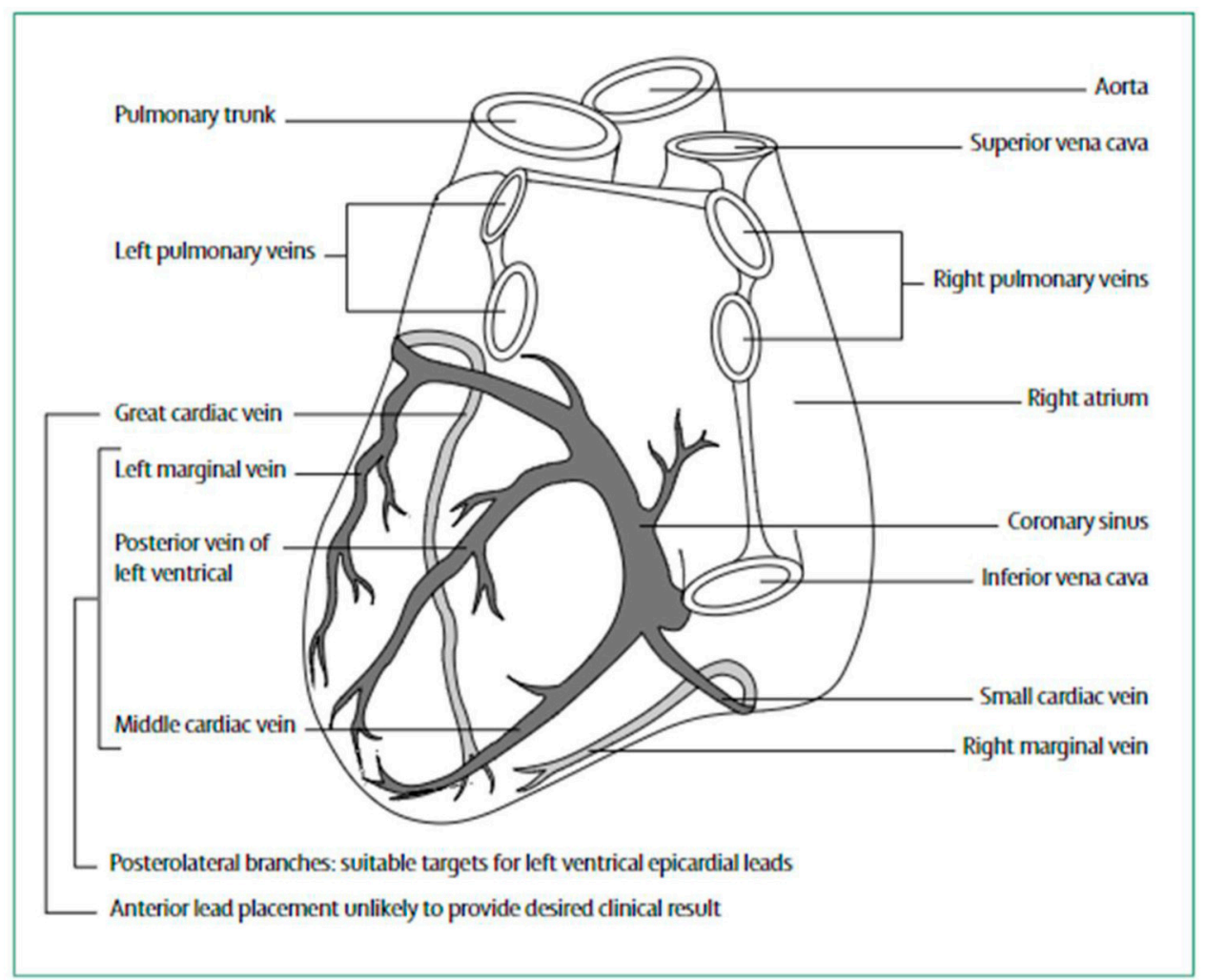

Figure 2. Diagrammatic presentation of heart showing positions for coronary venous lead placement. Reproduced with permission from reference [29].

Early attempts at biventricular pacing used leads that were not designed for cardiac venous placement. The Attain models 2187, 2188 (Medtronic, Inc., Minneapolis, MN) were stylet-driven and designed for atrial pacing. Lead lengths ranged from $58-85 \mathrm{~cm}$ and lead diameters ranged for 6.2-6.7 French. Although optimal outcomes could be achieved (Figure 3) [29], manipulation into small branches was frequently impossible. The subsequent development of novel narrow diameter leads easily advanced over guidewires has become the mainstream method for cardiac resynchronization therapy. The characteristics of state of the art left ventricular leads are summarized in Table 1.

Table 1. Cardiac venous (LV) leads sizes.

\begin{tabular}{cccc}
\hline Manufacture & Prodtct Line & Lead Body Diameter & Lead Length Range \\
\hline Abbott & Quartet $^{\mathrm{TM}}$ & $4.7 \mathrm{~F}$ & $75-92 \mathrm{~cm}$ \\
Medtronic & Attain $^{\mathrm{TM}}{ }_{\text {Performa }}{ }^{\mathrm{TM}}$ & $5.3 \mathrm{~F}$ & $78-88 \mathrm{~cm}$ \\
Boston Scientific & Acuity $^{\mathrm{TM}} \mathrm{X} 4$ & $5.2 \mathrm{~F}$ & $86-95 \mathrm{~cm}$ \\
Biotronik & Sentus $^{\circledR}$ & $4.8 \mathrm{~F}$ & $77-97 \mathrm{~cm}$ \\
\hline
\end{tabular}



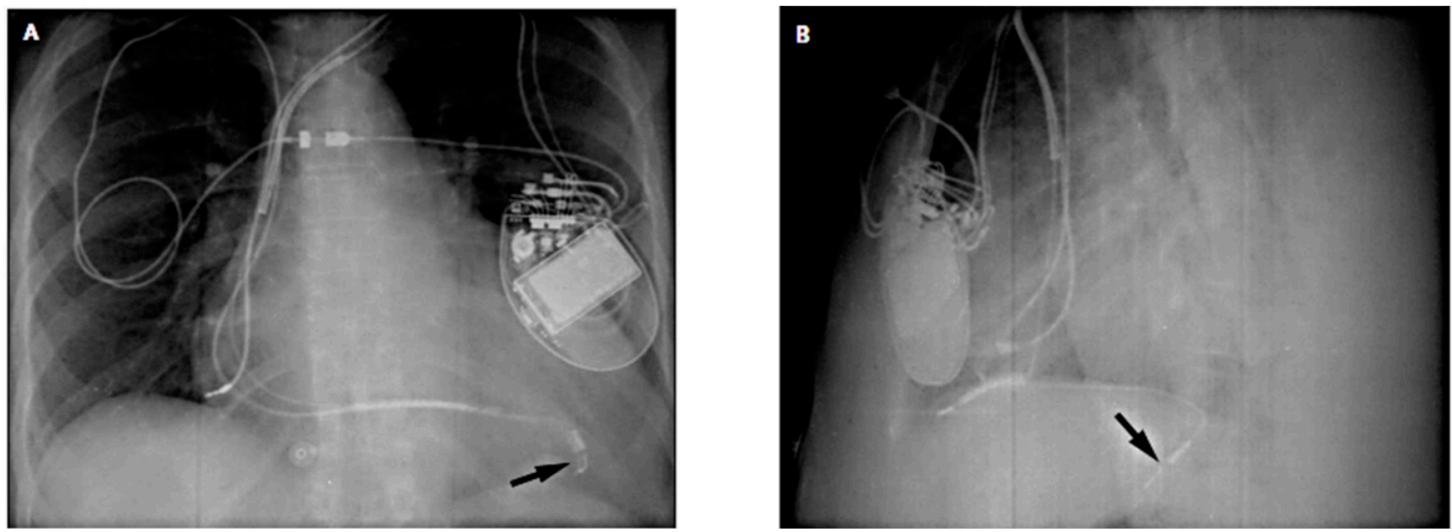

Figure 3. Chest radiographs showing lead placements. (A) Posteroanterior and (B) lateral chest radiographs showing tip of a large left ventricular lead (arrows) in a tributary of the middle cardiac vein. Despite proximity of the lead to the left hemidiaphragm, phrenic nerve stimulation did not take place. The right ventricular lead points anteriorly toward the rib cage. Reproduced with permission from reference [29].

A multi-center trial recently demonstrated that cardiac resynchronization can be achieved at least as well as biventricular pacing by substituting His bundle pacing (HBP) for cardiac venous pacing [30] (Medtronic, Inc., Minneapolis, MN). HBP is usually performed using the Select Secure (model 3830, $4 \mathrm{FR}, 69 \mathrm{~cm}$, Medtronic, Inc., Minneapolis, MN) pacing lead delivered through a fixed curve sheath (C315 HIS, Medtronic, Inc., Minneapolis, MN).

\section{Pressure Monitoring to Manage Heart Failure}

An estimated 57.4 million heart-failure-associated admissions occurred during the years 2001-2014. Although primary HF admission declined by an average annual rate of $3 \%$, heart failure remains a major public health burden worldwide [31]. Additionally, hospital readmissions remain a continued challenge in the management of the heart-failure patients. Although small gains have been made over the past $5-7$ years, over $20 \%$ of patients are still readmitted within 30 days and up to $50 \%$ are readmitted by 6 months [32].

Right heart catheterization remains an important diagnostic tool in cardiology's armamentarium, providing direct hemodynamic data to determine cardiac output (CO), evaluating intracardiac shunts, assessing valve dysfunction, diagnosing pulmonary hypertension, judging the effects of pharmacotherapy for heart failure, and evaluating patients prior to heart and/or lung transplantation [33].

In the 1980s, development of balloon flotation catheters which could be left in place for prolonged periods resulted in a surge in right heart catheterization in critical care units. Current standard thermodilution catheterization have 6-7.5 French. diameters and are $110 \mathrm{~cm}$ in length [34]. Unfortunately, pulmonary arterial catheterzation-guided management was associated with increased mortality and length of intensive care unit stay and led to a substantial decline in their use [33].

In recent years, improvements in the diagnostic power and availability of non-invasive cardiac imaging modalities, in addition to evidence of potential harm associated with pulmonary artery catheterization in patients in critical care, have resulted in an additional decline in right heart catheterization [33].

The public health and financial burden associated with heart failure has spurred efforts to detect early markers of clinical deterioration. A variety of implantable sensors have been designed to create opportunities for preemptive intervention to facilitate better heart failure care [35].

Sensors incorporated into CRT systems have been used to monitor hemodynamic, biochemical and electrical parameters. Piezoelectric sensors have been added to specialized right ventricular leads to monitor right ventricular pressure, peak endocardial acceleration and mixed venous oxygen 
saturation. The requirement for specialized leads with risks of lead-related complications has limited the applicability of these options [35]. The HeartPOD, a sensor lead placed at the inter-atrial septum and attached to a coil antenna used to measure left atrial pressure, was studied in the LAPTOP-HF outcomes trial. This trial was terminated early due to the perception of excess of implant-related complications [35-38].

Measurement of heart rate variability is not practical during atrial pacing or atrial tachycardias and may be altered by the use of cardiovascular medications [35]. Monitoring physical activity with accelerometers is a potentially useful adjunct, but not a viable option for prompt intervention. Intrathoracic impedance measurements may lack sensitivity and/or specificity in the presence of pleural effusion or concomitant pneumonia [35]. Early detection (via CRT devices) and prompt treatment of atrial arrhythmias may limit their adverse effects in heart-failure patients.

The search for practical implantable pressure sensor has been vigorously pursued with research and development for many years [39]. Despite the reduction in size of pacemakers and ICDs, they remain relatively large and have limited battery lives. An ideal pressure sensor would eliminate bulky hermetic sealing [40].

Recent rapid improvement in microfabrication has enabled development of smaller implantable, highly accurate pressure sensors capable of chronic monitoring. Microelectro-mechanical systems (MEMS) have significant miniaturization advantages [40]. The design of these sensors is fairly simple consisting of a scaled-down deformable membrane (diaphragm) and electrodes placed on the top and bottom within a sealed cavity [40].

The CardioMEMSTM HF System (St. Jude Medical, Inc. (Abbott), Little Canada, MN, USA) is the first (and only) FDA-approved heart failure monitor proven to significantly reduce heart-failure hospital admissions and improve quality of life [41]. The system is a miniaturized, implantable wireless monitoring sensor that is placed percutaneously (via the femoral venous approach) in the pulmonary artery to directly measure pulmonary arterial pressure. The CardioMems PA sensor (St. Jude Medical, Inc. (Abbott), Little Canada, MN, USA) is delivered to the pulmonary artery via a catheter utilizing a $0.018^{\prime \prime}$ over-the-wire system. The sensor is attached to the distal catheter by a tethering release cord. The sensor measures $15 \mathrm{~mm}$ in length, $3.5 \mathrm{~mm}$ in width, and $2 \mathrm{~mm}$ in thickness. Two polytetrafluoroethylene-coated nitinol loops (each measuring $10 \mathrm{~mm}$ in diameter) keep the sensor in contact with the vessel walls after its release [42]. As noted, the sensor resides in a completely sealed capsule that uses microelectromechanical systems (MEMS) technology which allows measurement stability and energy efficiency.

The system is capacitive. Pressure deforms the membrane, changing the distance between the electrodes and increasing the capacitance across the electrodes. An LC electrical circuit $(\mathrm{L}=$ inductor; $C=$ capacitor) stores energy and oscillates at the circuit's resonant frequency [43]. The sensor is powered by radiofrequency (RF) energy (it does not require a battery) and made of materials chosen for biocompatibility, insensitivity to alterations in body chemistry or biology, and durability. It is designed to last the lifetime of the patient.

Once implanted, the sensor wirelessly sends pressure readings to the portable external patient electronic system. The electronic unit is turned on and reads pressure measurements wirelessly while the patient lies on a special pillow containing an antenna $[44,45]$. The electronic unit uses audible and visual signals, prompting the patient to press a button to initiate a reading.

The portable external electronic unit and the specialized pillow help complete a system that permits the implantable sensor size to be small. The system allows patients to transmit PA pressure data (to a secure website) from their homes to their health care providers, allowing for personalized and proactive management geared toward reducing the likelihood of hospitalization [45].

\section{Minimally Invasive, Long-Term Heart Rhythm Monitoring}

An implantable loop recorder (ILR) is a small device (1.2-6.5 mL in volume; less than the size of a chewing gum pack or USB memory stick $[46,47])$ implanted subcutaneously around the 4 th 
intercostal space to the left of the sternum. These single-lead, electrocardiographic monitoring devices are used for diagnosis in patients with unexplained recurrent palpitations or syncope, for long-term monitoring in patients at risk for or with known atrial fibrillation (AF), cryptogenic stroke, for risk stratification in patients who have sustained a myocardial infarction and for individuals with certain genetic disorders. ILRs (with nearly 3 years of battery life) have a significantly greater diagnostic yield than 24-h Holter, 30-day event, or 30-day mobile cardiovascular telemetry monitors [46]. ILRs are exclusively diagnostic devices.

ILRs are leadless, have self-contained electrodes and solid-state loop memory capable of recording and storage of bipolar electrocardiogram (ECG) recordings when activated by a patient or bystander during symptomatic episodes [48]. The BioMonitor2 and BioMonitor3 (Biotronik, Lake Oswego, OR, USA) insertable cardiac monitors have antennae that are added to increase detection sensitivity. The antennae increase the device length (see Table 2 below). Each device primarily relies upon R-wave (ventricular activity) sensing. These devices can transmit data transtelephonically to a physician's office for review. Device interrogation may also take place using individual manufacturers' programmers.

Table 2. Implantable loop recorder (ILR) sizes.

\begin{tabular}{ccccc}
\hline Size & $\begin{array}{c}\text { Biotronik } \\
\text { BioMonitor 2 }\end{array}$ & $\begin{array}{c}\text { Biotronik } \\
\text { BioMonitor 3 }\end{array}$ & $\begin{array}{c}\text { Medtronic } \\
\text { Reveal LINQ }\end{array}$ & St. Jude Medical Confirm \\
\hline Length $(\mathrm{mm})$ & 88.4 & 77.5 & 44.8 & 56.3 \\
Width $(\mathrm{mm})$ & 15.2 & 8.6 & 7.2 & 18.5 \\
Thickness $(\mathrm{mm})$ & 6.2 & 4.6 & 4.0 & 8.0 \\
Volume $\left(\mathrm{cm}^{3}\right)$ & 5.0 & 1.9 & 1.2 & 6.5 \\
\hline
\end{tabular}

Although ILRs have significant strengths compared to noninvasive monitoring devices, they also have several important limitations. These include oversensing, undersensing and a propensity for false-positive AF detection. False-positive episodes may be related to an irregular sinus rhythm, noise in the recording, ventricular and/or atrial ectopy [48].

\section{Conclusions}

Miniaturization has dramatically reduced the size of cardiac pacemaker and implantable defibrillator systems, while simultaneously facilitating advances in their therapeutic capabilities.

Additional advances in leadless pacing are likely to revolutionize the field in the near future. Smaller, more maneuverable leads have made cardiac resynchronization therapy for heart failure a practical, mainstream technique. Implantable monitoring for heart-failure recipients promises to reduce readmission rates and facilitate ongoing assessment of various pharmacological therapeutic interventions. Implantable loop recorders extend our ability to find the cause of unexplained syncope, define the etiology of infrequent palpitations and unveil occult atrial fibrillation as a mechanism of cryptogenic stroke. Smaller, faster devices with even greater capabilities hold great promise to help patients live longer and better electrically.

Author Contributions: Conceptualization, R.G.T. Methodology, R.G.T., H.D.T. and P.S.S.; Validation, R.G.T., H.D.T. and P.S.S.; Formal Analysis, R.G.T.; Writing-Original Draft Preparation, R.G.T.; Writing-Review \& Editing, R.G.T., H.D.T. and P.S.S.; Supervision, R.G.T.

Funding: This research received no external funding.

Conflicts of Interest: Richard G. Trohman reports serving as an advisor to Boston Scientific/Guidant; receiving research grants from Boston Scientific/Guidant, Medtronic Inc., and St. Jude Medical (Abbott). Serving as a consultant for St. Jude Medical (Abbott); and receiving speakers fees or honoraria from Boston Scientific/Guidant CRM, Medtronic Inc., and St. Jude Medical (Abbott). Henry D. Huang reports serving as a consultant for Cardiofocus; receiving research grants from Medtronic. Parikshit S. Sharma reports receiving honoraria from Medtronic Inc., serving as a consultant for Medtronic Inc., Boston Scientific Inc., Abbott, and Biotronik Inc. 


\section{References}

1. Schwab, K. The Fourth Industrial Revolution: What it Means, How to Respond. Available online: https://www.weforum.org/agenda/2016/01/the-fourth-industrial-revolution-what-it-means-and-how-torespond/?_ga=2.108238338.1433365676.1566255770-882544073.1566255770 (accessed on 19 August 2019).

2. Miniaturization. Available online: https://en.wikipedia.org/wiki/Miniaturization (accessed on 19 August 2019).

3. Chugh, S.S.; Reinier, K.; Teodorescu, C.; Evanado, A.; Kehr, E.; al Samara, M.; Mariani, R.; Gunson, K.; Jui, J. Epidemiology of sudden cardiac death: Clinical and research implications. Prog. Cardiovasc. Dis. 2008, 51, 213-228. [CrossRef] [PubMed]

4. Zheng, Z.J.; Croft, J.B.; Giles, W.H.; Mensah, G.A. Sudden cardiac death in the United States, 1989 to 1998. Circulation 2001, 104, 2158-2163. [CrossRef] [PubMed]

5. Vassallo, P.; Trohman, R.G. Prescribing amiodarone: An evidence-based review of clinical indications. JAMA 2007, 298, 1312-1322. [CrossRef] [PubMed]

6. Watkins, L., Jr.; Mirowski, M.; Mower, M.M.; Reid, P.R.; Griffith, L.S.; Vlay, S.C.; Weisfeldt, M.L.; Gott, V.L. Automatic defibrillation in man. The initial surgical experience. J. Thorac. Cardiovasc. Surg. 1981, 82, 492-500. [PubMed]

7. Deyell, M.W.; Tung, S.; Ignaszewski, A. The implantable cardioverter-defibrillator: From Mirowski to its current use. BCM J. 2010, 52, 248-253.

8. Dresing, T. Cardiac Defibrillators. In Neuromodulation; Elliot Krames, P., Hunter, P., Ali, R., Eds.; Academic Press: Cambridge, MA, USA, 2009; pp. 817-882.

9. van Welsenes, G.H.; Borleffs, C.J.; van Rees, J.B.; Atary, J.Z.; Thijssen, J.; van der Wall, E.E.; Schalij, M.J. Improvements in 25 Years of Implantable Cardioverter Defibrillator Therapy. Neth. Heart J. 2011, 19, 24-30. [CrossRef] [PubMed]

10. Sattel, S. Everything You Need to Know About Capacitors. Available online: https://www.autodesk.com/ products/eagle/blog/everything-need-know-capacitors/ (accessed on 20 August 2019).

11. Implantable Cardioverter Defibrillators (ICDs). Available online: https://www.cardiovascular.abbott/us/en/ patients/living-with-your-device/arrhythmias/icds.html (accessed on 20 August 2019).

12. Weinstein, J. Subcutaneous Implantable Cardioverter Defibrillators. Available online: https://www.uptodate. com/contents/subcutaneous-implantable-cardioverter-defibrillators (accessed on 26 August 2019).

13. EMBLEM ${ }^{\mathrm{TM}}$ MRI S-ICD System. Available online: https://www.bostonscientific.com/content/gwc/en-US/ products/defibrillators/emblem-s-icd-system.html (accessed on 26 August 2019).

14. Lim, H.S. Overcoming the Limitations of the DF-4 Defibrillator Connector. J. Innov. Card. Rhythm Manag. 2013, 4, 1205-1207.

15. Bhargava, K. DF-4 Lead Connector: Innovative Technology, Unexpected Problems and Novel Solutions. Indian Pacing Electrophysiol. J. 2014, 14, 108-111. [CrossRef]

16. Pacemakers, from Start to Smallest. Available online: https://www.stmgb.org/www-smgb/media/SMGBPDFs/Medical\%20Services/Heart_Vascular/Micra_infographic.pdf (accessed on 20 August 2019).

17. Sutton, R.F.J.; Linde, C.; Benditt, D.G. History of electrical therapy for the heart. Eur. Heart J. Suppl. 2007, 9, I3-I10. [CrossRef]

18. Madias, C.; Trohman, R.G. Cardiac resynchronization therapy: The state of the art. Expert Rev. Cardiovasc. Ther. 2014, 12, 573-587. [CrossRef]

19. Lau, C.P.; Tse, H.F.; John Camm, A.J.; Barold, S.S. Evolution of pacing for bradycardias: Sensors. Eur. Heart J. Suppl. 2007, 9, I11-I22. [CrossRef]

20. Reddy, V.Y.; Exner, D.V.; Cantillon, D.J.; Doshi, R.; Bunch, T.J.; Tomassoni, G.F.; Friedman, P.A.; Estes, N.M., III; Ip, J.; Niazi, I.; et al. Percutaneous implantation of an entirely intracardiac leadless pacemaker. N. Engl. J. Med. 2015, 373, 1125-1135. [CrossRef]

21. Bhatia, N.; El-Chami, M. Leadless pacemakers: A contemporary review. J. Geriatr. Cardiol. 2018, 15, $249-253$. [PubMed]

22. Giudici, M.C.; Barold, S.S. Should the trend toward smaller lead sizes with pacemakers and defibrillators be reconsidered? Expert Rev. Cardiovasc. Ther. 2012, 10, 1337-1339. [CrossRef] [PubMed]

23. Trohman, R.G. Cardiac implantable electronic device infection: Formidable, frustrating, and increasingly frequent. Pol. Arch. Intern. Med. 2017, 127, 579-581. [CrossRef] [PubMed] 
24. Takano, A.; Sekita, G.; Watanabe, M.; Mukaida, H.; Komatsu, S.; Tabuchi, H.; Hayashi, H.; Tokano, T.; Sumiyoshi, M.; Nakazato, Y.; et al. Long-term reliability of sweet-tip type screw-in leads. J. Arrhythm. 2017, 33, 12-16. [CrossRef] [PubMed]

25. Perriello, B. Abbott Maintains Nanositm Halt on Docking Button Issue. Available online: https://www. massdevice.com/abbott-maintains-nanostim-halt-docking-button-issue/ (accessed on 22 August 2019).

26. Medtronic Announces First Human Implant of World's Smallest, Minimally Invasive Cardiac Pacemaker. Available online: https://www.dicardiology.com/article/medtronic-announces-first-human-implant-world\% E2\%80\%99s-smallest-minimally-invasive-cardiac?amp (accessed on 26 August 2019).

27. Reynolds, D.; Duray, G.Z.; Omar, R.; Soejima, K.; Neuzil, P.; Zhang, S.; Narasimhan, C.; Steinwender, C.; Brugada, J.; Lloyd, M.; et al. A leadless intracardiac transcatheter pacing system. N. Engl. J. Med. 2016, 374, 533-541. [CrossRef]

28. Trohman, R.G.; Huang, H.D.; Zimberg, R.; Serafini, N.J.; Sharma, P.S. Managing cardiac resynchronization therapy non-response: Conventional and unconventional techniques. J. Innov. Card. Rhythm Manag. 2018, 9, 3398-3405. [CrossRef]

29. Trohman, R.G.; Kim, M.H.; Pinski, S.L. Cardiac pacing: The state of the art. Lancet 2004, 364, 1701-1719. [CrossRef]

30. Upadhyay, G.A.; Vijayaraman, P.; Nayak, H.M.; Verma, N.; Dandamudi, G.; Sharma, P.S.; Saleem, M.; Mandrola, J.; Genovese, D.; Oren, J.W.; et al. On-treatment comparison between corrective His bundle pacing and biventricular pacing for cardiac resynchronization: A secondary analysis of His-SYNC. Heart Rhythm 2019. [CrossRef]

31. Akintoye, E.; Briasoulis, A.; Egbe, A.; Dunlay, S.M.; Kushwaha, S.; Levine, D.; Afonso, L.; Mozaffarian, D.; Weinberger, J. National trends in admission and in-hospital mortality of patients with heart failure in the United States (2001-2014). J. Am. Heart Assoc. 2017, 6, e006955. [CrossRef] [PubMed]

32. O'Connor, C.M. High Heart failure readmission rates: Is it the health system's fault? JACC Heart Fail. 2017, 5, 393. [CrossRef] [PubMed]

33. Callan, P.; Clark, A.L. Right heart catheterisation: Indications and interpretation. Heart 2016, 102, $147-157$. [CrossRef] [PubMed]

34. Swan-Ganz Thermodilution Catheters. Available online: https://edwardsprod.blob.core.windows.net/media/ De/devices/monitoring/hemodynamic\%20monitoring/e7158-swan-ganz-thermo-spec-sheet.pdf (accessed on 22 August 2019).

35. Liu, P.S.; Tse, H.F. Implantable sensors for heart failure monitoring. J. Arrhythm. 2013, 29, 314-319.

36. Baliga, R.R. Implantable Hemodynamic Monitoring for Heart Failure. Available online: https://www.acc.org/latest-in-cardiology/ten-points-to-remember/2017/07/12/12/22/implantablehemodynamic-monitoring-for-heart-failure (accessed on 14 September 2019).

37. Abraham, W.T.; Adamson, P.B.; Costanzo, M.R.; Eigler, N.; Gold, M.; Klapholz, M.; Maurer, M.; Saxon, L.; Singh, J.; Troughton, R. Hemodynamic monitoring in advanced heart failure: Results from the LAPTOP-HF Trial. J. Card. Fail. 2016, 22, 940. [CrossRef]

38. Abraham, W.T.; Perl, L. Implantable hemodynamic monitoring for heart failure patients. J. Am. Coll. Cardiol. 2017, 70, 389-398. [CrossRef] [PubMed]

39. Clausen, I.; Thomas Glott, T. Development of clinically relevant implantable pressure sensors: Perspectives and challenges. Sensors 2014, 14, 17686-17702. [CrossRef] [PubMed]

40. Yu, L.; Kim, B.J.; Meng, E. Chronically implanted pressure sensors: Challenges and state of the field. Sensors 2014, 14, 20620-20644. [CrossRef] [PubMed]

41. Abraham, W.T.; Adamson, P.B.; Bourge, R.C.; Aaron, M.F.; Costanzo, M.R.; Stevenson, L.W.; Strickland, W.; Neelagaru, S.; Raval, N.; Krueger, S.; et al. Wireless pulmonary artery haemodynamic monitoring in chronic heart failure: A randomised controlled trial. Lancet 2011, 377, 658-666. [CrossRef]

42. Shavelle, D.M. How to Implant the CardioMEMS ${ }^{\mathrm{TM}}$ Heart Failure Sensor. Available online: https://citoday. com/pdfs/cit0118_F5_Shavelle.pdf (accessed on 24 August 2019).

43. Circuit, L.C. Available online: https://en.wikipedia.org/wiki/LC_circuit (accessed on 14 September 2019).

44. CARDIOMEMSTM HF SYSTEM. Available online: https://www.cardiovascular.abbott/us/en/patients/livingwith-your-device/heart-failure/pulmonary-pressure-artery-monitoring/cardiomems-hf-system/ht-tab/setup.html (accessed on 15 September 2019).

45. Cardiomems Technology Fact Sheet. Available online: http://s1.q4cdn.com/166440495/files/doc_downloads/ Heart\%20Failure/Euope-CardioMEMS-Technology-Fact-Sheet.pdf (accessed on 24 August 2019). 
46. Mittal, S.; Joshi, R. Implantable Loop Recorder. Available online: https://emedicine.medscape. com/article/1920236-overview?src=ppc_google_rlsa-traf_mscp_emed_md_us\&gclid=CjwKCAjw1_ PqBRBIEiwA71rmtVzmRvAPU1Vnp7syrIvjq2AUNWmjU4yU5b2f716LAnSjUv4FLwqqPBoCfDkQAvD_ BwE\#a1 (accessed on 21 August 2019).

47. Implantable Loop Recorder. Available online: https://en.wikipedia.org/wiki/Implantable_loop_recorder (accessed on 21 August 2019).

48. Lee, R.; Mittal, S. Utility and limitations of long-term monitoring of atrial fibrillation using an implantable loop recorder. Heart Rhythm 2018, 15, 287-295. [CrossRef]

(C) 2019 by the authors. Licensee MDPI, Basel, Switzerland. This article is an open access article distributed under the terms and conditions of the Creative Commons Attribution (CC BY) license (http://creativecommons.org/licenses/by/4.0/). 